\title{
CORRECTION
}

\section{Correction to: Weber Syndrome}

\author{
Marina Romozzi ${ }^{1}$ [ $\cdot$ Giulia Bramato ${ }^{2} \cdot$ Marco Luigetti $^{1}$
}

(c) The Author(s) under exclusive licence to Belgian Neurological Society 2022

\section{Correction to: Acta Neurologica Belgica \\ https://doi.org/10.1007/s13760-021-01861-5}

The keywords were incorrectly published in the original publication. The complete correct keywords are given below.

Keywords: Weber syndrome; Brainstem syndrome; Stroke; Brain MRI

The original article has been corrected.

Publisher's Note Springer Nature remains neutral with regard to jurisdictional claims in published maps and institutional affiliations.

The original article can be found online at https://doi.org/10.1007/ s13760-021-01861-5.

$\checkmark$ Marina Romozzi

marinaromozzi@gmail.com

1 UOC Neurologia, Fondazione Policlinico Universitario Agostino Gemelli IRCCS, Rome, Italy

2 UOC Geriatria, Fondazione Policlinico Universitario Agostino Gemelli IRCCS, Rome, Italy 